\title{
Age composition, growth, and reproductive biology of yellow catfish (Peltobagrus fulvidraco, Bagridae) in Ce Lake of Hubei Province, Central China
}

\author{
Ling Cao • Biyu Song • Jinmiao Zha • \\ Chengtai Yang • Xinfu Gong • Jianbin Li • \\ Weimin Wang
}

Received: 28 March 2007 / Accepted: 12 February 2008 / Published online: 20 May 2008

(C) Springer Science + Business Media B.V. 2008

\begin{abstract}
This study presents fundamental information on the reproductive biology, size and age composition, and growth of yellow catfish, Peltobagrus fulvidraco. Sampling was carried out monthly from Ce Lake in Hubei province from January 2004 and December 2004. Overall female/male $(F / M)$ sex ratio was 1.08 , not significantly different from expected 1.0 ratio. But sex ratio $(F / M)$ of the
\end{abstract}

L. Cao $\cdot$ C. Yang $\cdot$ W. Wang $(\bowtie)$

College of Fisheries, Key Lab of Agricultural Animal

Genetics, Breeding and Reproduction of Ministry

of Education, Huazhong Agricultural University,

Wuhan 430070, China

e-mail:wangwm@mail.hzau.edu.cn

L. Cao

School of Natural Resources and Environment,

University of Michigan,

Ann Arbor, MI 48109, USA

B. Song

School of Resource and Environmental Science,

Wuhan University,

Wuhan, Hubei 430072, China

\section{J. Zha}

State Key Laboratory of Environmental Aquatic Chemistry, Research Center for Eco-Environmental Sciences,

Chinese Academy of Sciences,

P.O. Box 2871, Beijing 100085, China

X. Gong $\cdot$ J. Li

Fuer Fish Nursery Limited Company of Huangshi,

Huangshi City, Hubei 435000, China spawning group was 1.14:1 with skewness towards females $(p<0.05)$. The smallest sexually mature male and female massed 20.51 and $16.93 \mathrm{~g}$, and measured 100.1 and $94.3 \mathrm{~mm}$ in total length, respectively. Reproductive period for this species is from April to August when GSI is considerably higher than the rest months $(p<0.05)$. The highest GSI values were measured from May to July for both sexes and this period was presumably the peak spawn. First maturation occurred at age $1^{+}$for both sexes. Fish of age $1^{+}$and $2^{+}$comprised the greatest portion of spawners. The absolute fecundity (AF) of $P$. fulvidraco ranged from 657 to 11,696 eggs per fish, with mean AF value of 3,570 \pm 122 (S.D.) eggs per fish, varying considerably at given length, weight and age. The fecundity relative to total length $(F / L)$ fluctuated from 58 to 680 eggs $/ \mathrm{mm}$, with a mean value of $246 \pm 34$ (SD) eggs $/ \mathrm{mm}$, and fecundity relative to total weight $(F / W)$ varied from 29-133 eggs/g, with a mean value of $67 \pm 7$ (SD) eggs/g. P. fulvidraco is a single spawner, with low fecundity compared with other Bagrid fish.

Keywords Peltobagrus fulvidraco - Age - Growth · Reproductive biology Fecundity

\section{Introduction}

Yellow catfish, Peltobagrus fulvidraco, belongs to Bagridae family. With both high economic and nutritional value, feeding upon cladocerans and 
zooplankton, P. fulvidraco is one of the promising freshwater species for both semi-intensive and intensive culture in East and South Asia (Liu 1997). It is widely distributed in lakes along the midstream and downstream of Yangtze River Basin in central China, with most abundance in Hubei Province (Du 1963). Based on recent assessment of this species, the natural stock is probably at a reduced reproductive capacity and at risk of being harvested unsustainably (Liu 1997; Luo et al. 2005). Knowledge of the reproductive biology and the estimation of fecundity and egg production are fundamental in the study of the population dynamics of fish species (Hunter et al. 1992; Murua et al. 2003), as they are basal to quantify reproductive capacity at both individual and population levels of a fish species. Manipulation of fish's reproductive system under artificial conditions also requires an understanding of natural spawning patterns and other influential factors based on information of the species' reproductive biological characters such as size-at-sexual maturity, the duration and periodicity of spawning.

However, the information available on the reproductive biology of $P$. fulvidraco is still incomplete. Detailed descriptions of fecundity, egg production, reproductive season, and the relationships between somatic and gonadal growth have not been well documented. Previous studies on the reproductive biology of $P$. fulvidraco have indicated that this fish of each geographical population spawns at different seasons with different levels of spawning activity; being maximum during peak spawning from middle May to Middle July in Liangzi Lake (Du 1963), from June to July in Honghu Lake (Ma 1991), from April to June in Poyang Lake (Liu 1997) and at lower levels during the rest months of the spawning period. Moreover, there were inconsistent reports on the spawning pattern of this species. Some indicated that $P$. fulvidraco was batch spawner with asynchronous oocyte development and, therefore, the population egg production should be estimated combining batch fecundity, spawning fraction and the number of active females in the adult population (Hu et al. 1993; Wang 1999). According to Hunter et al. (1992), multiple spawning fish are called indeterminate serial or batch spawners, if the annual fecundity is not fixed at the beginning of spawning and the standing stock of present oocytes in the ovary is continuously replaced by new developing oocytes during one spawning cycle. On the other hand, fish that have a fixed fecundity prior to the onset of spawning are called single spawners or determinate serial spawners. Yang (1994) indicated that this species belonged to determinate serial spawner. Similar results were reported by Liu and Zhang (2003). Therefore, determining the spawning patterns is of great importance for estimating the potential annual fecundity of this fish and its ability to recover from human fishery impact. Spawning strategy, fecundity and egg production of this fish species varied annually and/or spatially among stocks in relation to condition and environmental factors, which is of considerable importance because it influences stock reproductive potential, and thus has a direct implication on a population's ability to sustain harvesting.

The aim of this research was to investigate the spawning activity and spawning pattern of yellow catfish in Ce Lake from January to December 2004, thus providing comprehensive information for its age, growth, reproductive biology study and future sustainable use. This was achieved by investigating and assessing important reproductive parameters such as sexual maturity, sex ratio, gonadosomatic index values, spawning seasonality, monthly specific variation of oocyte size-frequency distribution and fecundity of this fish species. In addition, condition factor $(K)$ is explored as a potential factor governing variation in fecundity (Murua et al. 2006).

\section{Materials and methods}

Study site and sampling procedure

Ce Lake, with an area of $9.4 \mathrm{~km}^{2}$, located in the east of Hubei Province in central China (Fig. 1). The width of Ce Lake ranges from constrictions of less than $2 \mathrm{~m}$ to large pools several hundred meters across. Mean water depth of this lake is about $2.6 \mathrm{~m}$. Mean annual DO (dissolved oxygen) concentration in this freshwater lake is above $4 \mathrm{mg}^{-1} \mathrm{l}^{-1}$ throughout of the year. The $\mathrm{pH}$ varies from 6.5 7.5. The lake was surrounded by rice fields and fish ponds. The exposed parts of the lakeshore of Ce Lake contain a plant community with mostly small herbaceous species. The fine sediment is nutrient-rich and consists mainly of clay. Vegetation cover is generally low and decreasing towards the lake. 
Fig. 1 Map of the study location: the Ce Lake in Hubei Province, central China. Six roman numerals indicate six sampling sites locating at upstream, midstream and downstream, respectively in Ce Lake
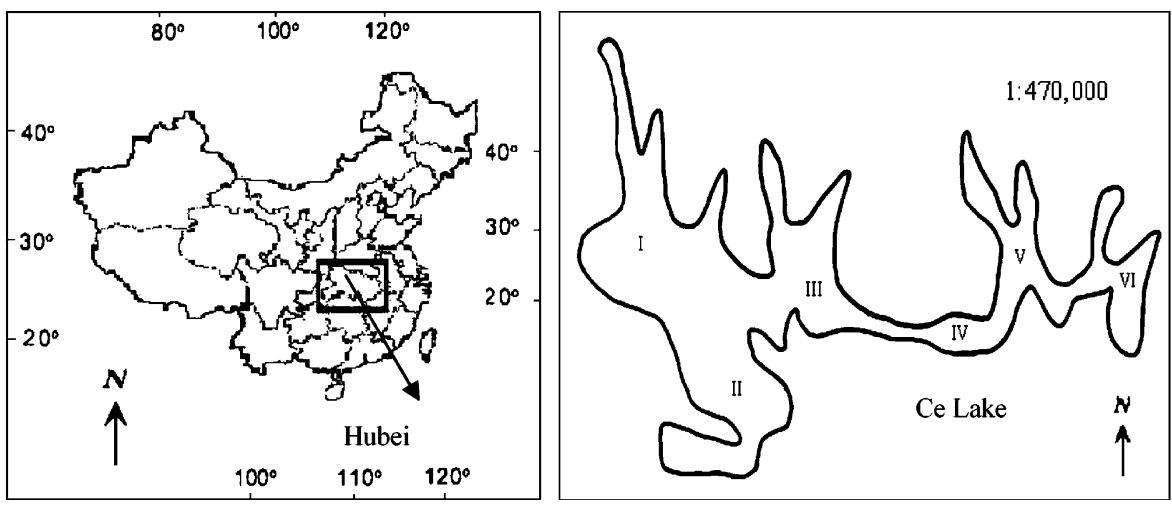

Monthly sampling was carried out from January to December 2004. From April to August, sampling frequency was twice a month because this was the time when P. fulvidraco actively spawned. A total of 768 samples were obtained in Ce Lake. Fish were collected using seine nets, consisting of two $40 \mathrm{~m}$ long wings with a $3 \mathrm{~cm}$ mesh and a $100 \mathrm{~m}$ long packet with a $2 \mathrm{~cm}$ mesh, each of which had a length of $10 \mathrm{~m}$. Specimens collected were anesthetized using tricaine methanesulfonate (MS 222), and fixed in 10\% buffered formalin for later analysis.

Total length, caudal peduncle length (the oblique distance from the insertion of the anal fin to the midpoint of the end of the hypural plate) and caudal peduncle depth (the least depth of this structure from the mid-line of the ventral surface) of each sample were measured to the nearest $0.1 \mathrm{~mm}$ with dial calipers. Total weight of fish was weighed to the nearest $0.01 \mathrm{~g}$. Sex of each fish was differentiated by sexual characteristics (genitals of males) or by examining its gonads under a dissecting microscope. Size at maturity was determined for each sex by assessing samples collected during the reproductive season.

Age and growth

The sagittal otoliths of each fish were removed, cleaned and stored dry in gelatin capsules. They were later placed in methyl salicylate in a black dish and examined under a dissecting microscope at $\times 40$ magnification using reflected light (Morgan et al. 2000). The distance between the outer edge of the translucent zone and the periphery of each otolith was measured. Each distance was always measured along the same axis and recorded to the nearest $0.025 \mathrm{~mm}$.
For convenience, the relative marginal increment was subsequently referred to as marginal increment. The age of each fish at the time of capture was estimated using otolith information. Growth curves were then fitted to the length at body weight of each fish using a non-linear technique.

\section{Gonadosomatic index}

Gonads were separated from fish body and weighed to the nearest $0.0001 \mathrm{~g}$ in the laboratory (Johnston and Knight 1999) and subsequently preserved in $10 \%$ formalin within $24 \mathrm{~h}$ of capture for subsequent histological analyses following a standard histological protocol (Pearce 1965). Seasonal change in gonad mass for both sexes was determined using the gonadosomatic index (GSI). GSI was calculated as GSI $(\%)=100 \times$ gonad weight (total body weightgonad weight) ${ }^{-1}$ for each fish and all values were averaged monthly (Anderson and Gutreuter 1983). Spawning periods were determined from monthly evolution of GSI.

Oocyte size-frequency distributions

Ovarian condition of females was categorized using the classification of Heins and Baker (1993): (1) latent (stage I), (2) early maturing (stage II), (3) late maturing (stage III), (4) maturing (stage IV), (5) ripening (stage V) and (6) spent (stage VI). Ovarian stages at IV and $\mathrm{V}$ were considered reproductive, while stages I, II, III and VI were considered nonreproductive (Heins and Baker 1993). Reproductive condition of males was determined by visual examinations of testes. Mature males have large and opaque testes. Males that have small and transparent testes 
were considered latent. The numbers of oocytes in ovaries at spawning period (from April to August) were estimated by the gravimetric hydrated-oocyte method (Hunter et al. 1985), as the average of three replicates. Subsamples of $1 \mathrm{~g}$ each, were extracted from anterior, middle and posterior parts of the right ovary, and weighed to the nearest $0.0001 \mathrm{~g}$. The number of hydrated oocytes was counted in each subsample under a binocular microscope (Murua and Motos 2006). The diameter of oocytes was measured as the average of major and minor axes. The size-frequency distribution of the oocytes in each ovary was recorded and histograms were constructed from pooled data for estimating spawning pattern and frequency.

Fecundity

The condition factor (CF) of the sampled fish $(n=$ 218) were analyzed. Monthly samples of fish captured within the same study area and the same period were analyzed to relate to seasonal variations in fecundity. The values of condition factor was calculated as $\mathrm{CF}=$ 100 (total body weight-gonad weight) $/ 1^{3}$.

Mature ovaries were identified from their external appearance and the extent to which they filled the body cavity. Fifty-nine ovaries at stage IV and V were chosen from fish collected from April to August of 2005, when GSI values were highest, to estimate absolute fecundity and relative fecundity. The oocyte packing density in the ovary was investigated to ensure that the subsamples were representative of the entire ovary (Murua et al. 2003). Natural logarithm transfer of oocyte density was used to comply with the assumption of homoscedasticity. The numbers of oocytes per gram of ovarian tissue were examined using ovaries of 59 females in six sub-samples taken at different locations (anterior, mid and posterior) of each lobe (left and right). All ovaries used to estimate were histologically screened to check for the occurrence of postovulatory follicles. Ovaries with recent postovulatory follicles were eliminated for fecundity calculations, since their presence indicated part of the batch had ovulated and the fecundity thus would be underestimated.

The number of oocytes in these chosen ovaries was estimated by the gravimetric hydrated-oocyte method (Hunter et al. 1985) as mentioned above. The fecundity of each fish was then estimated as the weighted mean density of the three subsamples multiplied up to determine the total ovary mass. If the coefficient of variation was higher than $5 \%$, then additional samples were counted (Murua et al. 2003). The absolute fecundity of yellow catfish was recorded as the number of mature eggs in the ovaries of ripe samples. Relative fecundity (number of eggs per unit weight) was determined as the number of mature oocytes in relation to total weight or total length (Hotosa et al. 2000).

Absolute fecundity $=$ egg numbers per 1 gram ovary

$$
\times \text { ovary weight }(\mathrm{g})
$$

Relative fecundity $(\mathrm{F} / \mathrm{W})$

$$
=\text { absolute fecundity/total weight }(\mathrm{g})
$$

Statistical analysis

Sex ratio was determined for each population by using pooled fish from monthly collections. Deviations from the expected 1:1 sex ratio were determined using a chi-square test. The relationship between fecundity and body length, ovary-free body weight and age were analyzed with linear or non-linear regression using Pearson's correlation analysis (Bagenal 1978). All values were $\log _{10}$ transformed prior to analysis and tested for normality and homogeneity of slopes to satisfy the assumptions of statistical analysis. $T$ test was performed to test if there were significant differences between the ratio of caudal peduncle length (CPL) and total length (L) of females and that of males. Data were analyzed statistically by using SPSS (version 11.5) statistical software package (SPSS Inc., Chicago, USA). Differences were considered significant at an alpha level of 0.05 .

\section{Results}

Sex ratio

According to dissecting microscope examination and secondary sexual characteristics, a total of 768 fish was sexed, of which 398 (51.8\%) and 370 (48.2\%) were females and males, respectively. Overall female/male (F/M) sex ratio was 1.08 , not significantly different from expected 1:1 ratio $\left(\chi^{2}=0.098, d f=1, p=0.325\right.$; Table 1$)$. 
But sex ratio (F/M) of the spawning group was 1.14:1 with skewness towards females $(p<0.05)$. The highest sex ratio of $1.74(\mathrm{~F} / \mathrm{M})$ was observed in May. From April to June, deviations from 1:1 ratio were found in P. fulvidraco with skewness towards females $(p<0.05)$. However, from July to August, deviations from 1:1 ratio were found with skewness towards males $(p<$ $0.05)$. There were no significant differences from expected 1:1 ratio for the rest months $(p>0.05)$.

Size and age distribution

There were significant differences of the length of mature $P$. fulvidraco between sexes. The sizes of females ranged from 92.7 to $175.7 \mathrm{~mm}$, while that of males ranged from 91.5 to $216.5 \mathrm{~mm}$ in total length. Gonads were macroscopically visible for individuals $>100 \mathrm{~mm}$ (total length) for males and $>90 \mathrm{~mm}$ (total length) for females. The distribution of sexes by size class (Table 2) showed a significant predominance of females in specimens smaller than $150 \mathrm{~mm}$ in TL, while a significant predominance of males larger than $160 \mathrm{~mm}(p<0.05)$.

Based upon otolith checking, it was found that age $0^{+}$fish were primarily of stage I and had a very low GSI and gonad weight of almost zero. Age $1^{+}$and higher fishes were represented in all other gonad stages (II-VI), with values of GSI and gonad weight indicative of reproductive potential. In all gonad stages, especially IV and V, the predominance of ages $1^{+}$and $2^{+}$was very evident. Spawning stock of $P$.

Table 1 Sex ratio of females to males (F/M) of $P$. fulvidraco in Ce Lake in 2004

\begin{tabular}{lcccl}
\hline $\begin{array}{l}\text { Sampling } \\
\text { months }\end{array}$ & $\begin{array}{l}\text { No. } \\
\text { (females) }\end{array}$ & $\begin{array}{l}\text { No. } \\
\text { (males) }\end{array}$ & $\begin{array}{l}\text { Sex ratio } \\
(\mathrm{F} / \mathrm{M})\end{array}$ & \multicolumn{1}{l}{$\begin{array}{l}\text { Chi-square } \\
\text { test }\end{array}$} \\
\hline JN & 34 & 33 & 1.03 & $p>0.05$ \\
FE & 30 & 31 & 0.97 & $p>0.05$ \\
MA & 31 & 29 & 1.07 & $p>0.05$ \\
AP & 47 & 35 & 1.34 & $p<0.05$ \\
MA & 40 & 23 & 1.74 & $p<0.05$ \\
JU & 48 & 32 & 1.50 & $p<0.05$ \\
JL & 22 & 33 & 0.67 & $p<0.05$ \\
AU & 27 & 38 & 0.71 & $p<0.05$ \\
SE & 37 & 40 & 0.93 & $p>0.05$ \\
OC & 23 & 21 & 1.10 & $p>0.05$ \\
NV & 34 & 31 & 1.10 & $p>0.05$ \\
DE & 25 & 24 & 1.04 & $p>0.05$ \\
Total & 398 & 370 & 1.08 & $p>0.05$ \\
\hline
\end{tabular}

Table 2 The total length distribution of both sexes by size class of $P$. fulvidraco $(n=768)$ collected in this study

\begin{tabular}{lrrr}
\hline \multirow{2}{*}{ Total length $(\mathrm{mm})$} & \multicolumn{3}{c}{ Number of specimens } \\
\cline { 2 - 4 } & Female & Male & Total \\
\hline $90-100$ & 72 & 10 & 82 \\
$100-110$ & 97 & 34 & 127 \\
$110-120$ & 47 & 23 & 70 \\
$120-130$ & 54 & 15 & 69 \\
$130-140$ & 36 & 17 & 53 \\
$140-150$ & 55 & 22 & 77 \\
$150-160$ & 30 & 11 & 41 \\
$160-170$ & 9 & 45 & 54 \\
$170-180$ & 2 & 89 & 91 \\
$180-190$ & 0 & 68 & 68 \\
$190-200$ & 0 & 29 & 29 \\
$200-210$ & 0 & 6 & 6 \\
$210-220$ & 0 & 1 & 1 \\
Sex ratio & 398 & 370 & 768 \\
\hline
\end{tabular}

fulvidraco $(N=332)$ is comprised mostly of age $1^{+}$ and age $2^{+}$fish during reproductive season (Table 3 ). Age $1^{+}$fish were less than $120 \mathrm{~mm}$ TL (both sexes combined accounts for $32.9 \%$ of total), age $2^{+}$fish ranged from 120 to $170 \mathrm{~mm}(49.7 \%)$, age $3^{+}$or higher fish exceeded $130 \mathrm{~mm}(15.0 \%)$. First maturation occurred at age $1^{+}$for both sexes. The smallest sexually mature male and female massed 20.51 and $16.93 \mathrm{~g}$, respectively, and measured 100.1 and $94.3 \mathrm{~mm}$ in total length, respectively.

\section{Sex characters}

Through $T$ test, there were significant differences between the ratio of caudal peduncle length (CPL) and total length $(L)$ of females $(n=50)$ and that of males $(n=50 ; t=-15.6019, p<0.0001)$. In males, the $\mathrm{CPL} / L$ of males during the whole year ranged from 0.1310 to 0.1662 which were all higher than 0.13 ; while those of females ranged from 0.1120 to 0.1299 , all less than 0.13 . No difference was detected between the ratios of caudal peduncle depth and body depth of both sexes $(p>0.05)$.

Following Keys formula, the relationship between total weight $(W, \mathrm{~g})$ and total length $(L, \mathrm{~mm})$ is typically expressed as $W=a L^{b}$ ( $a, b$ indicate constants; Maack and George 1999). Based on data pooled from the whole year, the length-weight exponential relationship of $P$. fulvidraco was shown in Fig. 2. 
Table 3 Age composition of spawning stock of $P$. fulvidraco $(N=332)$ in Ce Lake during reproductive season

\begin{tabular}{|c|c|c|c|c|c|c|c|}
\hline \multirow[t]{2}{*}{ Age } & \multicolumn{2}{|c|}{ Total length (mm) } & \multicolumn{2}{|c|}{ Total weight (g) } & \multicolumn{2}{|c|}{ Oocyte diameter (mm) } & \multirow[t]{2}{*}{ Percentage $(\%)$} \\
\hline & Mean $\pm 95 \%$ & Range & Mean $\pm 95 \%$ & Range & Mean $\pm 95 \%$ & Range & \\
\hline 1 & $106.3 \pm 8.4$ & $94.3-119.8$ & $26.87 \pm 9.03$ & $16.93-36.28$ & $1.25 \pm 0.16$ & $1.019-1.449$ & 32.9 \\
\hline 2 & $146.6 \pm 4.1$ & $124.8-168.5$ & $51.67 \pm 10.59$ & $36.90-74.40$ & $1.27 \pm 0.24$ & $1.105-1.575$ & 49.7 \\
\hline 3 & $151.2 \pm 9.2$ & $132.1-171.5$ & $55.44 \pm 9.65$ & $38.13-70.46$ & $1.31 \pm 0.09$ & $1.159-1.397$ & 10.2 \\
\hline 4 & $169.0 \pm 7.5$ & 151.9-203.9 & $76.58 \pm 21.27$ & $61.46-119.50$ & $1.45 \pm 0.22$ & $1.282-1.684$ & 4.8 \\
\hline Not aged & $107.7 \pm 6.5$ & $102.1-114.9$ & $27.24 \pm 8.36$ & $21.33-36.85$ & $1.12 \pm 0.18$ & $0.999-1.325$ & 2.4 \\
\hline
\end{tabular}

Spawning season and patterns

As an indicator of reproductive condition, GSI were calculated for both sexes using all available fish and for each sex separately (Fig. 3). Water temperature was also shown in Fig. 3 as a potential factor governing variation in GSI. For females, the mean
GSI increased from April, reached a peak in May $(17.29 \%)$. It thereafter decreased slightly in June. In July and August, it increased again to form the second peak $(12.77 \%)$ which was obviously smaller than the first peak. In September, it lowered down rapidly to approach the lowest values and remained at a low level between October and March with a maximum
Fig. 2 The length-weight relationship of $P$. Fulvidraco: a female: $n=398$; b male: $n=370$
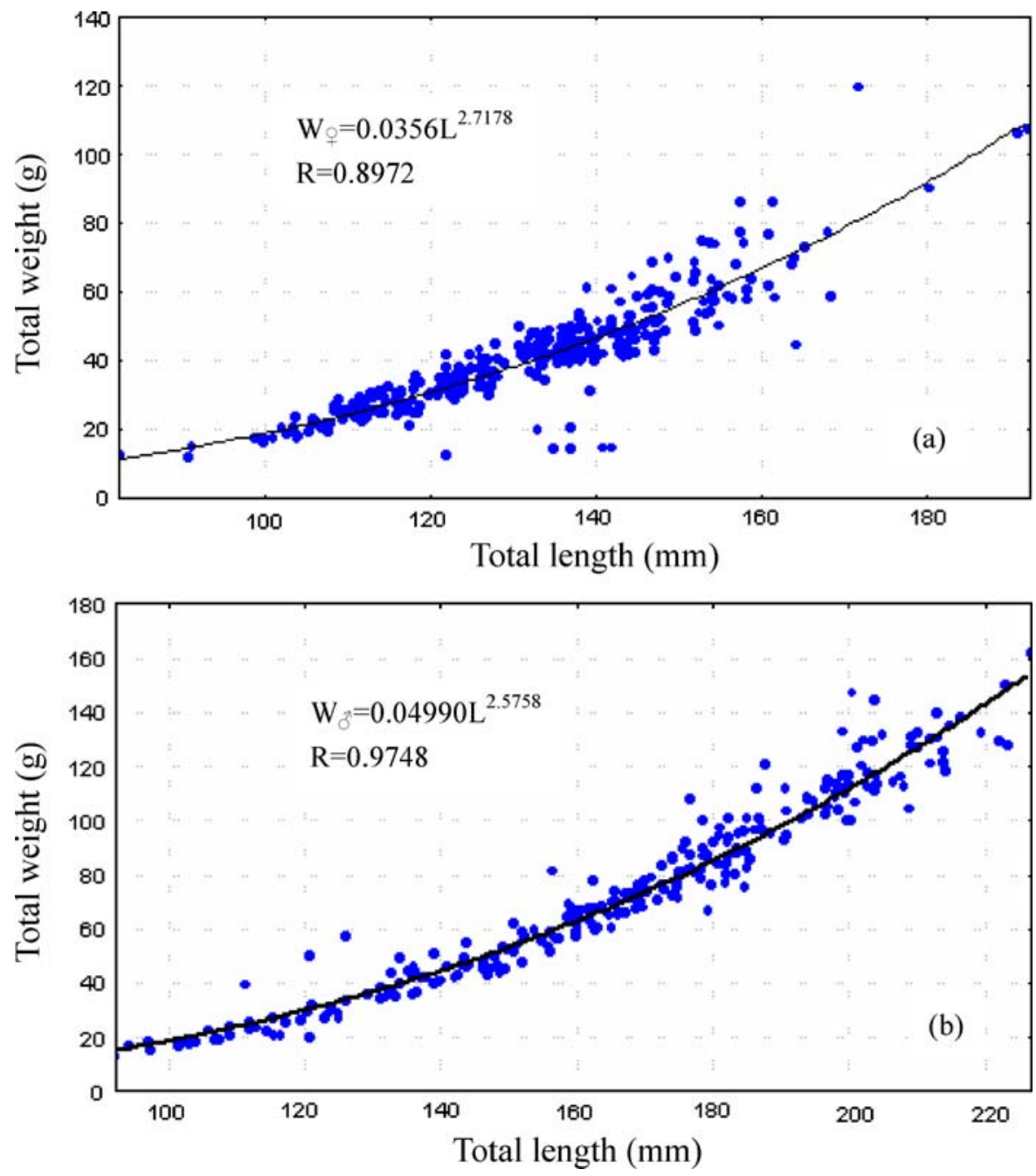
Fig. 3 Annual changes in gonadosomatic index (mean values $\pm \mathrm{SD}$ ) for male and female $P$. fulvidraco in $\mathrm{Ce}$ Lake: a females: $n=398$; b males: $n=370$; c monthly changes of mean water temperature in Ce Lake
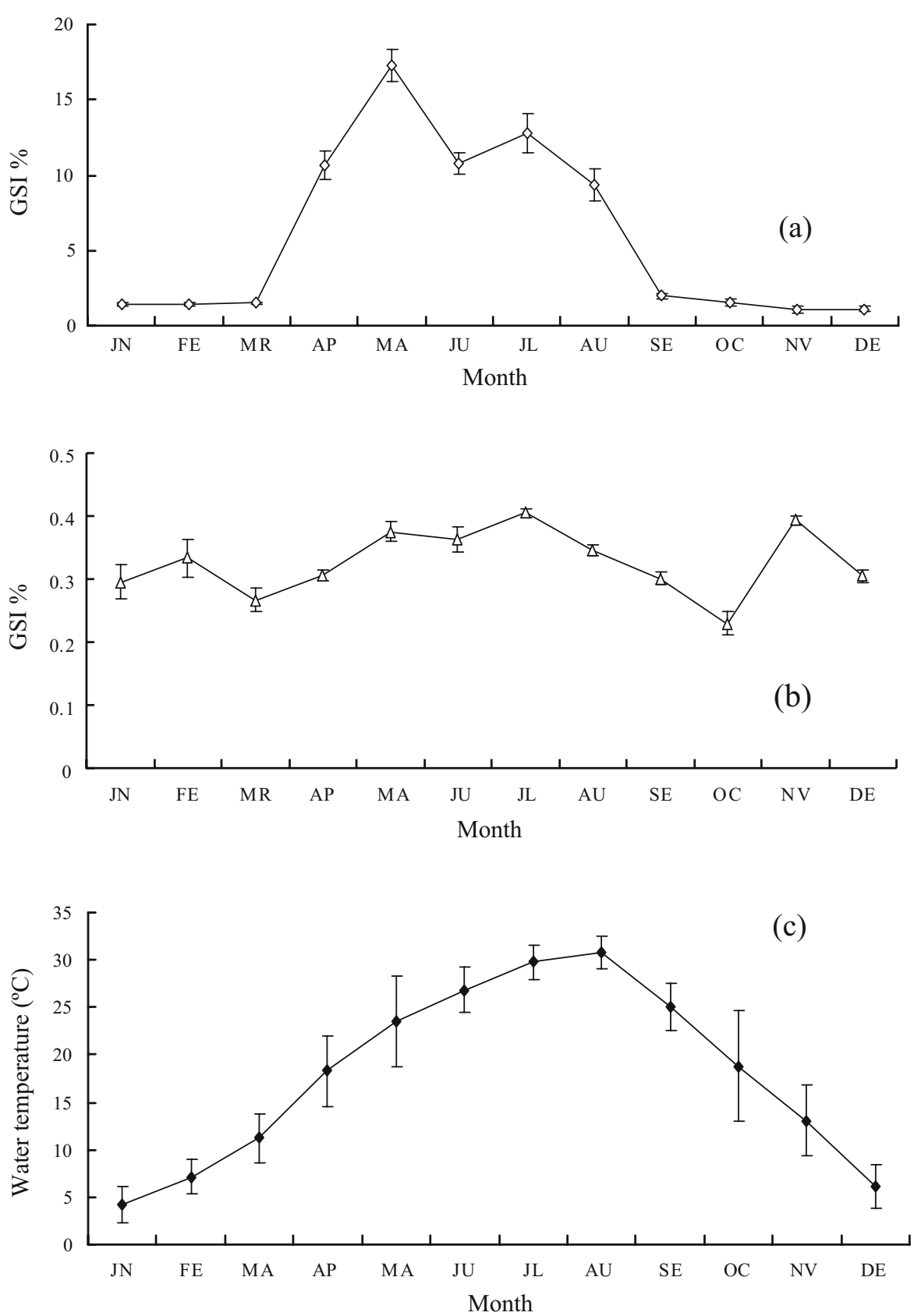

value of $2 \%$. The GSI curve of females fluctuated more obviously than that of males. For males, there were two peaks of GSI in the spawning season. One was from May to August, which was concurrent with that of females. The other was shaped in November. The minimum individual GSI was in October $(0.23 \%)$. Besides, the GSI of males had another two peaks in the non-spawning season, from February to March and from November to December, respectively.
Thus, the reproductive period for this species in this particular environment was from April to August when GSI was considerably higher than the rest months. During spawning season, GSI values were $0.31-0.41 \%$ for males and $9.38-17.29 \%$ for females, respectively. The highest female GSI values were measured from May to July and this period was presumably the peak spawn.

Ovaries from 156 females were prepared for histological analyses. There were two distinct phases 
during oocyte growth. The primary growth phase (PGP) included stage I, II and III. Secondary growth phase (SGP) included stage IV, V and VI. Oocyte size-frequency distribution was studied in the mature fish (Fig. 4a-1). It showed the developmental sequence of maturation. In stage II and stage III, oocyte diameter ranged from $0.5-0.6$ and $0.7-0.9 \mathrm{~mm}$, respectively. Yolked oocytes ranged from 1.1-1.85 and 1.4-1.9 $\mathrm{mm}$ for maturity stages IV and V, respectively. The frequency of larger oocytes ranging from 1.4-1.9 mm for the $\mathrm{V}$ stage was higher than that of stage IV. The oocyte diameter for stage VI dropped to the range of $0.3-1.3 \mathrm{~mm}$, which largely belonged to the small oocytes in the range of $0.3-0.7 \mathrm{~mm}$. The
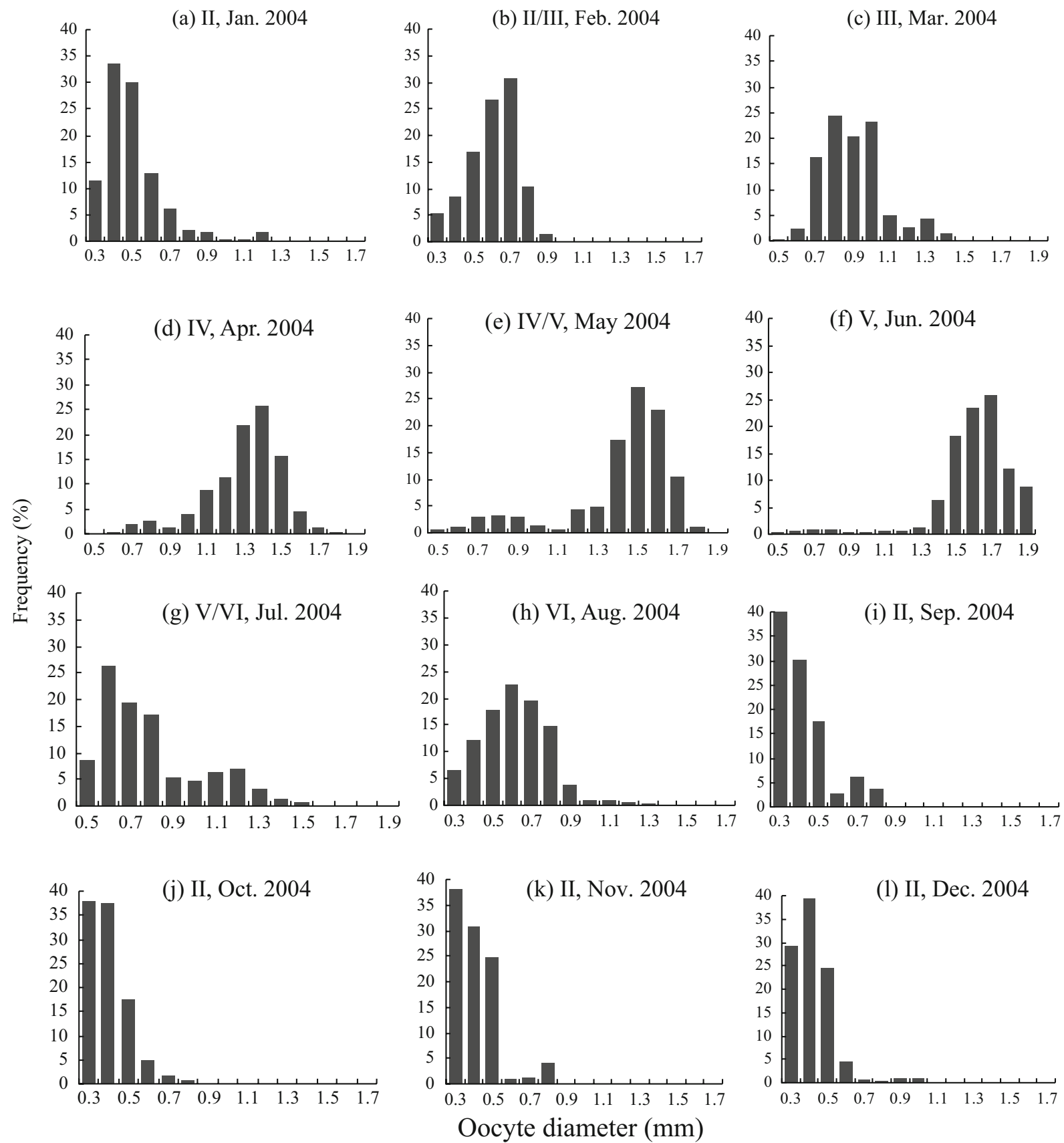

Fig. 4 Monthly oocyte size-frequency distributions and ovarian stages variations of $P$. fulvidraco in Ce Lake in 2004. Each panel corresponds to an individual fish 
period from April to August was considered as spawning period. After spawning, individuals returned to stage II for overwintering and never developed into stage III till next March. This distribution pattern of the developing oocytes, indicated that $P$. fulvidraco is a determinant spawner or single spawner, spawning only once during its reproductive period. Based on this, the estimated absolute fecundity is the annual fecundity. None of total weight, total length and age of this species was significantly related to oocyte diameter $(p>0.05)$. After logarithmic transformation of all variables, there were no significant correlations among them, neither.

Fecundity

Annual changes of condition factor (CF) of $P$. fulvidraco were shown in Fig. 5. It peaked in February and October for both sexes. The CF of females ranged from 11.65-15.58 with a mean value of 13.29, in which April-August were obviously lower than those of the rest $(p<0.05)$. The CF of males ranged from $11.79-15.35$ with a mean value of 13.82 and reached nadir in July. Except in January and October, there was no significant difference of CF for males in the rest months, while $\mathrm{CF}$ of females fluctuated fiercely throughout the year.

All the oocytes were counted but only the more advanced ones (size $>1.1 \mathrm{~mm}$ ) were used for fecundity estimates. The fecundity was estimated from yolked oocytes in 100 ovaries macroscopically staged as IV and V from April to August. The absolute fecundity (AF) of $P$. fulvidraco ranged from 657 (total length, $94.3 \mathrm{~mm}$ ) to 11,696 (total length, $175.7 \mathrm{~mm}$ ) eggs per fish, with mean AF value of 3,570 \pm 122 (S.D.) eggs per fish, varying considerably at given length, weight and age. The fecundity relative to total weight (F/W) varied from 29-133 eggs/g, with a mean value of $67 \pm 7(\mathrm{SD}) \mathrm{eggs} / \mathrm{g}$.

All the correlation coefficients calculated between fecundity and each of these independent variables, were judged to be either moderately or high and statistically significant $(p<0.05)$ indicative of a very good model for a fecundity study, considering additionally that fecundity was not completely depended on the size of the fish, but is affected by various other factors such as the aquatic environment and more importantly the condition of the fish (Hotosa et al. 2000). The relationships of AF and relative fecundity $(\mathrm{F} / \mathrm{W})$ with total weight $(W)$ were presented in Fig. 6. There was a positive linear correlation between AF and relative fecundity $(\mathrm{F} / \mathrm{W})$ with total weight $(p<0.05)$. The correlation can be best described as: $\mathrm{AF}=108.0624 \mathrm{~W}-1611.2737, R=$ $0.8765, \quad r^{2}=0.7683, n=74 ; \quad \mathrm{F} / \mathrm{W}=$ $3.082101 \mathrm{~W}^{1.11342065}, R=0.8110, r^{2}=0.6578, \mathrm{n}=74$, respectively. The relationships between fecundity and age $(t)$ were presented in Fig. 7. There was positive linear correlation existed between absolute fecundity $(F)$ and relative fecundity $(F / W)$ with age $(p<0.05)$, though relative fecundity $(F / W)$ dropped when fish reached age 4 . Their correlation can be best described as: $\mathrm{AF}=2,282.2890 \times t-769.0522, R=0.8510, r^{2}=$ $0.7242, n=74 ; \quad F / W=128.6138 \times t+6.987002, \quad R=$ $0.8025, r^{2}=0.6440, n=74$, respectively.
Fig. 5 Annual changes of condition factor $(C F)$ for both sexes of $P$. fulvidraco in Ce Lake

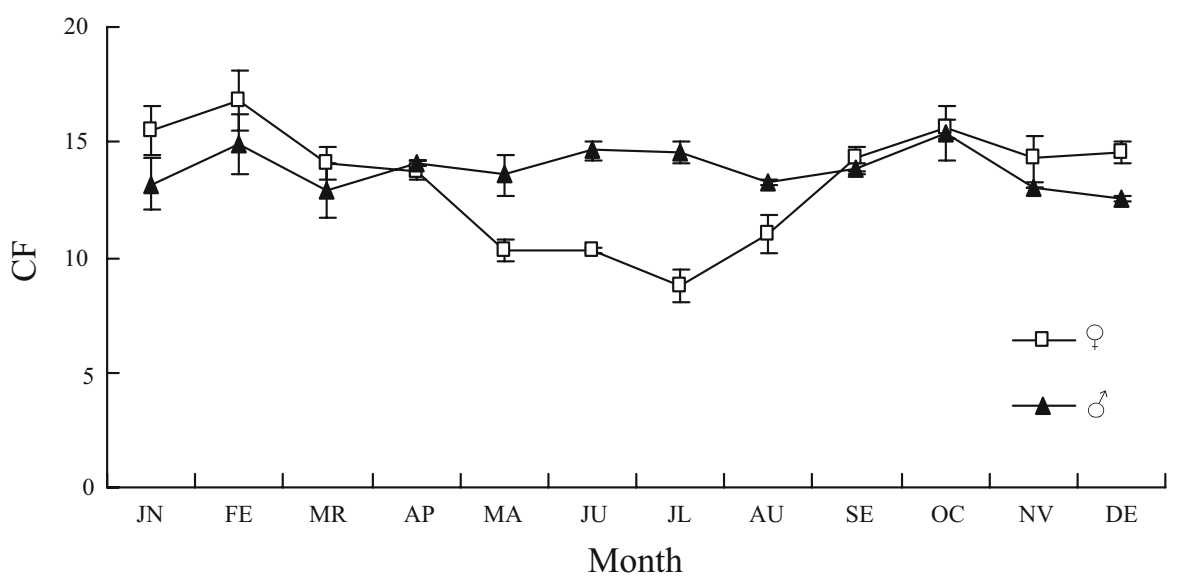


Fig. 6 Relationships between fecundity and total weight of $P$. fulvidraco $(N=$ 74) in Ce Lake: a absolute fecundity $(A F)$ and total weight $(W)$; b relative fecundity $(F / W)$ and total weight $(W)$
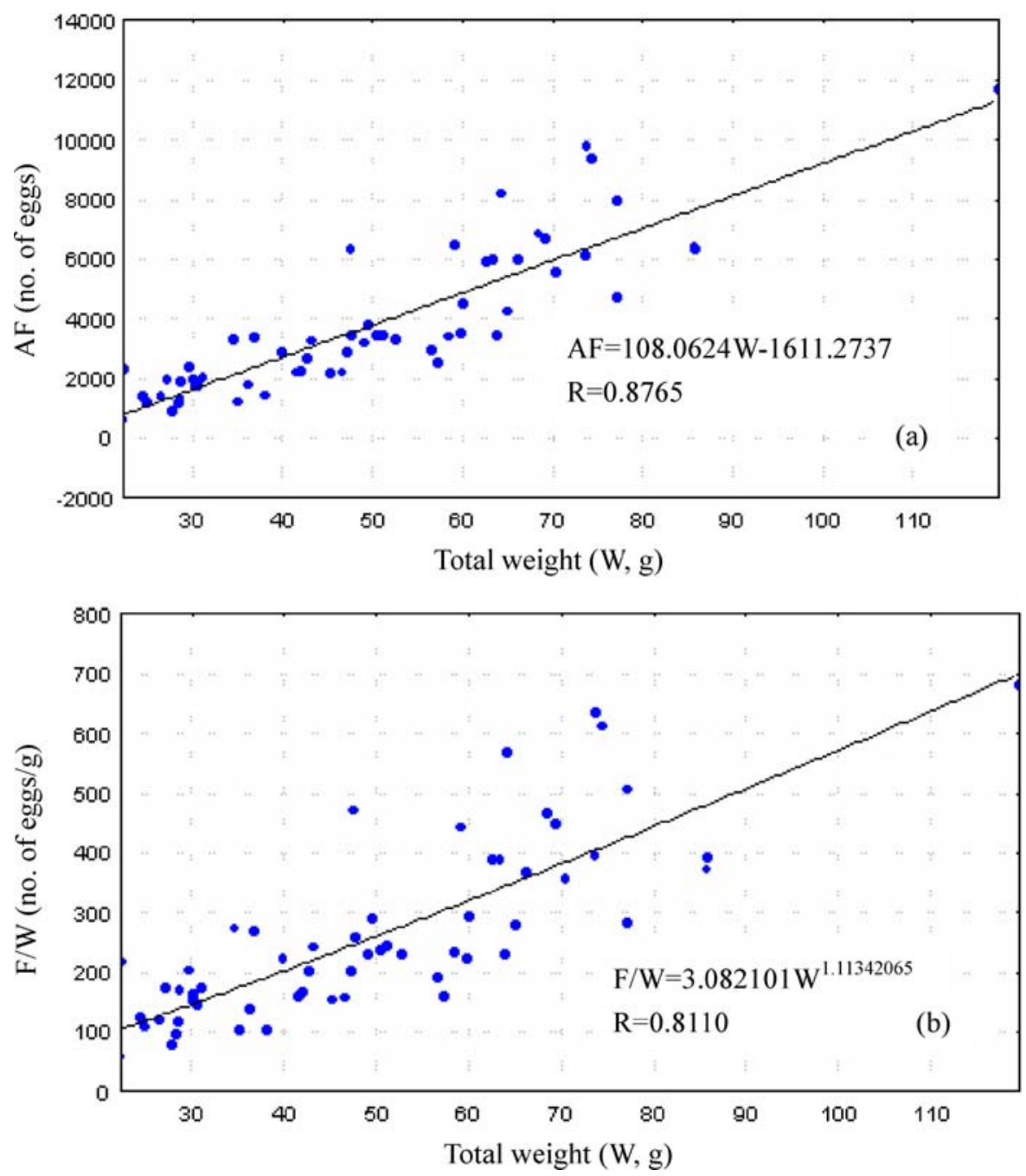

\section{Discussion}

Comparison on the reproductive biology of $P$. fulvidraco among different parts of their range during reproductive season was presented in Table 4. Differences do exist for the Ce Lake $P$. fulvidraco population relative to populations in the North. Variations in spawning period, size and age of spawners and differences in absolute fecundity provide biological evidence for specific spawning characteristics in the Ce Lake.

Sex differentiation is one of the most important indexes in fish biology study and also the preliminary step for artificial breeding. Both morphological differentiation and ultrasonography methods can be used to determine fish sex (Mattson 1991). Three types of sexual characteristics differentiation could be summarized in fishes: (1) body size of females $>$ that of males; (2) body size of females < that of males; (3) similar size of both sexes with partial differences on morphology (Lin and Lei 2004). Type I is most common in favor of high production of females. The rest two types make males easier to chase females and give better protection to their offspring, thus enhancing their fertilization rates, hatching rates and survival rates. In the present study, based on our observation, P. fulvidraco belonged to type II, since males were always much bigger than females at the same age. Larger size of males than females, higher abdominal capability of females than males and significant differences on contrasting total weight and net body weight indicated that female $P$. fulvidraco utilized more energy for reproduction, while males distributed more energy for growth performance. Our observa- 
Fig. 7 Relationships between fecundity and age of P. fulvidraco $(N=74)$ in $\mathrm{Ce}$ Lake: a absolute fecundity $(A F)$ and age; b relative fecundity $(F / W)$ and age
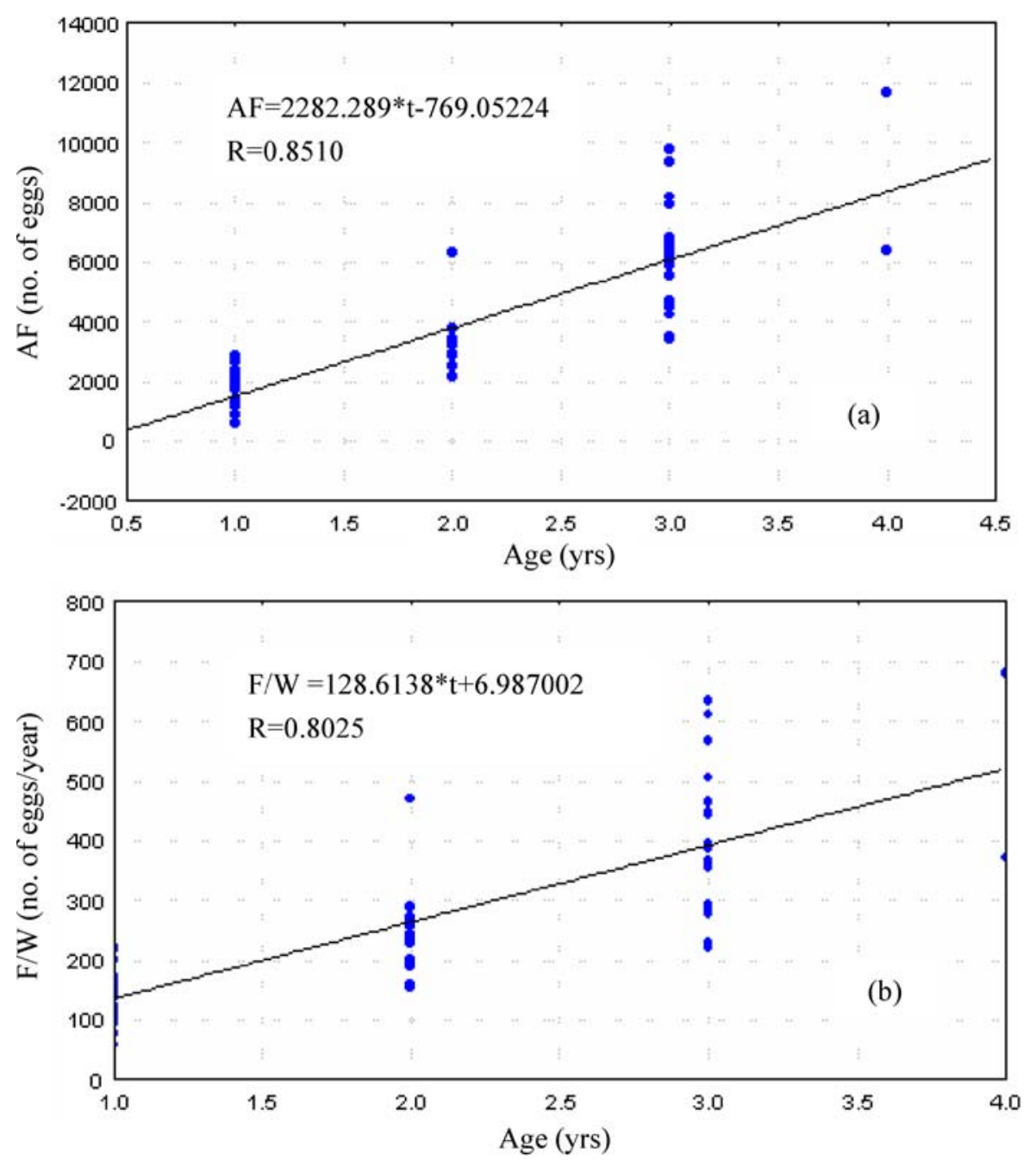

tions on the morphology of external sex organs such as genital in the male $P$. fulvidraco could be also used as an efficient way to differentiate sex, which were in good consistence with the conclusions from the earlier studies (Wang et al. 2002; Lin and Lei 2004). Moreover, the CPL/L ratios were all higher than 0.13 during the whole year in males, while the reverse were found in females. Compared with other bagrid fish (Wang et al. 2002; Xiao et al. 2002), this would be a useful standard for sex differentiation of $P$. fulvidraco.

Sex ratio of a certain population is one of the most important parameters for population ecological study. Though overall sex ratio was close to expected 1.0 ratio $(p>0.05)$, there has significant difference between the sex ratios in the spawning season and nonspawning season. The sex ratio for the spawning group was 1.14:1 with skewness towards females ( $p<$ 0.05 ). During early spawning season (April-June), the number of female of $P$. fulvidraco was higher than that of male, while at the end of spawning season (July-August), males were more. In contrast, during non-spawning season, sex ratios were not bias significantly from 1:1. Sex ratio difference was also found in P. fulvidraco at different size. Males were predominant in larger size group $(>160 \mathrm{~mm})$, which was consistent with previous study (Lei and Lin 2004). This could be considered as one of the reproductive strategies of $P$. fulvidraco. During postspawning period, since females already consumed lots of energy for spawning, more male fish would better safeguard the fertilized eggs and offspring (Wang et al. 2002). However, different sex ratios of spawning group were reported before in other lakes. In Honghu 
Table 4 Comparison of spawning population demographics of $P$. fulvidraco in Ce Lake (present study) and throughout their geographic range in China, listed from south to north

\begin{tabular}{|c|c|c|c|c|c|c|c|}
\hline Location & $\begin{array}{l}\text { Sampling } \\
\text { no. }\end{array}$ & $\begin{array}{l}\text { Fish size }{ }^{a} \\
(\mathrm{~mm})\end{array}$ & $\begin{array}{l}\text { Fish } \\
\text { weight }^{\mathrm{b}}(\mathrm{g})\end{array}$ & $\begin{array}{l}\text { Fish age } \\
\text { (year) }\end{array}$ & $\begin{array}{l}\text { Spawning } \\
\text { season }\end{array}$ & $\begin{array}{l}\text { Absolute } \\
\text { fecundity }\end{array}$ & $\begin{array}{l}\text { Sex ratio } \\
(F / M)\end{array}$ \\
\hline Ce Lake (present study) & 768 & 94.3 & 16.93 & $1^{+}, 2^{+}$ & Apr. Aug. & $657 \sim 11,696$ & $1.14: 1$ \\
\hline Honghu Lake (Ma 1991) & 221 & 78.0 & 11.90 & $1^{+}, 2^{+}$ & May Aug. & $794 \sim 4,873$ & $0.87: 1$ \\
\hline Liangzi Lake (Du 1963) & 376 & - & - & - & May Jul. & $1,086 \sim 4,496$ & - \\
\hline Zhangdu Lake (Luo et al. 2005) & 370 & 90.0 & 10.00 & $2^{+}, 3^{+}$ & Apr. Jun. & - & - \\
\hline Dongting Lake (Xiao et al. 2003) & 155 & 102.9 & 30.67 & $1^{+}, 2^{+}$ & Apr. Aug. & $1,345 \sim 7,208$ & - \\
\hline Poyang Lake (Liu 1997) & 587 & 80.0 & 13.90 & $0^{+}, 1^{+}, 2^{+}$ & Apr. Jun. & $1,134 \sim 12,412$ & $1.23: 1$ \\
\hline Oujiang River (Lei and Lin 2004) & 212 & 95.4 & - & - & Apr. Jun. & - & $1.79: 1$ \\
\hline Taihu Lake (Zou and Tian 1998) & 165 & 112.0 & 28.50 & $2^{+}, 3^{+}$ & May Jul. & - & - \\
\hline Tanghu Lake (Qiu et al. 2000) & 3,241 & 126.0 & 28.00 & $1^{+}, 2^{+}, 3^{+}, 4^{+}$ & Jun. Aug. & $1,405 \sim 14,960$ & $1.81: 1$ \\
\hline
\end{tabular}

${ }^{\text {a }}$ Fish size at first sexual maturity

${ }^{\mathrm{b}}$ Fish weight at first sexual maturity

${ }^{\mathrm{c}}$ Fish age refers to the age of the majority of spawning fish in that site.

Lake, the sex ratio $(F / M)$ was $0.87: 1$ with skewness towards males during reproductive season (Ma 1991). On the reverse, it was 1.23:1 with skewness towards females for Poyang Lake (Liu 1997). For Oujiang River and Tanghu Lake, it was 1.79:1 and 1.81:1, respectively, with extremely bias toward females (Qiu et al. 2000; Lei and Lin 2004). In general, the sex ratio of reproductive-aged fishes is known to vary with the age and size at which fish begin to participate in breeding, resistance to physical environmental stress in each sex, water temperature and/or $\mathrm{pH}$ during the sex determination period, population density, and other factors (Liu 1997).

The most common practice for the determination of a species spawning season is the establishment of its GSI, oocyte diameter frequency, as well as microscopic and histological examination of the gonads (Wang et al. 2002). The fact that, during January, February, September to December 2004, the mean GSI of female fish were less than $2 \%$ and the ovary of no fish exceeded stage III, demonstrates that P. fulvidraco undergoes little gonadal development in the early spring, autumn and winter. However, the marked increase that occurs in mean GSIs, oocyte diameters and the stage in ovarian development from April to August shows that the gonads mature rapidly between late spring and summer (April August). The data on the monthly trends exhibited by the oocyte size-frequency and gonadal stages provide strong evidence that $P$. fulvidraco spawns between April and August, with spawning activity peaking from
May to July, which was consistent with previous study in Donting Lake (Xiao et al. 2003). For Liangzi Lake, reproduction was found to occur from May to late July ( $\mathrm{Du}$ 1963). The reproductive season of $P$. fulvidraco from Honghu Lake, occurred from May to August with a peak in June and July (Ma 1991).

To verify the spawning pattern of $P$. fulvidraco is of great importance for fecundity estimation. However, there was no agreement in former studies. Wang et al. (2002) reported it as a batch spawner and spawned twice during one spawning season per year. Liu and Zhang (2003) insisted that it is a single spawner. In the present study, we agree with the second viewpoint. Though there were two peaks of GSI for females and four for males, the ovaries returned to stage II after spawning and never developed till the new spawning cycle. Thus there was little chance for $P$. fulvidraco to return stage IV after first spawning and spawn the second time.

Analysis of age distribution of $P$. fulvidraco during reproductive season indicated that age $1^{+}$and age $2^{+}$ fish dominate reproduction in Ce Lake, which was in accordance with the results in Honghu Lake and Dongting Lake (Ma 1991; Xiao et al. 2003). This may be related to over-exploitation which leads to the degradation of natural resources. However, in Zhangdu Lake and Taihu Lake, the majority of spawning fish are age $2^{+}$and age $3^{+}$(Zou and Tian 1998; Luo et al. 2005). Surprisingly, for Poyang Lake, fish at age $0^{+}$is one of the major populations among spawning fish (Liu 1997). The age structure in 
Tanghu Lake was random and no majority existed (Qiu et al. 2000). First maturation size and weight of P. fulvidraco in Ce Lake was lower compared to Dongting Lake, Taihu Lake and Tanghu Lake, which further proved that the natural stock of this species was under pressure and rational management for protection should be proposed.

The fecundity estimation showed that $P$. fulvidraco had a reproductive strategy common to many other bagrid catfish (Qiu et al. 2000; Wang et al. 2002). It had a low absolute fecundity ranged from 657 to 11,696. According to previous studies, absolute fecundity of $P$. fulvidraco in Honghu Lake, Poyang Lake, Liangzi Lake and Tanghu Lake ranged 794 4,873, 1,132 12,412, 1,086 4,496, and 1,405 14,960, respectively (Du 1963; Ma 1991; Liu 1997; Qiu et al. 2000). Among five geographical groups, absolute fecundity of $P$. fulvidraco in Ce Lake was close to that of Poyang Lake and Tanghu Lake, and higher than the rest two groups. In response to environmental differences, the ability of changing its reproductive biology is usually thought of as an adaptive strategy to differing environments. These changes may have effects beyond the individuals, and may alter ecological processes in the environment by changing many direct and indirect ecological interactions. Local adaptation is a process that also may produce differences in reproduction. Life history parameters, reproductive traits in particular, are known to vary across environmental gradients in some fishes (Mazzoni and Iglesias-Rios 2002). The proposed reasons for these findings include changes in stream hydrology, sediment input and temperature. Relative fecundity (29-133 eggs $\cdot \mathrm{g}^{-1}$ ) of $P$. fulvidraco in Ce Lake was close to other bagridea catfish (Yang 1994; Wang et al. 2002). Though absolute fecundity is low, with high quality eggs, high fertilization rates and careful protection for offspring, P. fulvidraco gain high survival rates of their juveniles (Wang et al. 2002). This ecological strategy proved that under the pressure of over fishing, $P$. fulvidraco could still survive as the predominant species, which was consistent with the study in Honghu Lake (Ma 1991).

Management of many exploited fish populations is based on spawner-recruitment models. Traditional recruitment models assume that the reproductive potential of a population is proportional to its spawning stock biomass (Murua and Motos 2006). This implies that the survival rates of offspring are independent of parental age, body size or condition (Cardinale and Arrhenius 2000), and that total relative fecundity and thus annual egg production per unit mass of adult stock are invariable over time. However, there is increasing evidence indicating that direct proportionality between spawning stock biomass and reproductive potential may not exist. This could even be more evident when the production of eggs per unit stock spawning biomass may vary substantially among years depending upon environmental conditions (e.g. temperature and food availability) during the spawning season (Murua and Motos 2006). Based on present study, four protection recommendations for P. fulvidraco are proposed accordingly. First, larger mesh size $(>3 \mathrm{~cm})$ of seine nets should be used to replace the old smaller ones during common harvesting. Second, harvesting time should avoid the peak reproductive season (May to July) of $P$. fulvidraco and harvest fish size larger than $15 \mathrm{~cm}$ with a minimum age of $2^{+}$. Third, artificial breeding, larvae releasing to natural water bodies and artificial culture of $P$. fulvidraco should be conducted to reinforce the population and lessen the pressure of natural stocks (Xiao et al. 2002). Finally, sewage and industrial wastewater discharging to these lakes should be controlled and monitored and better waste treatment methods should be investigated (Xiao et al. 2003).

Acknowledgement We would like to thank the four master students from Huazhong Agricultural University for help in collection samples and providing data. Thanks are further extended to Zhiguo Zhang for help in the processing of samples. Special thanks go to the workers of Ce Lake aquafarm, without whose generosity and cooperation, the entire work would not have been possible. This study is funded by "National Key Technology R\&D Program in Eleventh-FiveYear Plan" titled as "High quality and high efficiency freshwater aquaculture technology research program". The accession number is 2006BAD03B07. And "The integrated demonstration of safe fishery production". The accession number is 2006BAK02A22.

\section{References}

Anderson RO, Gutreuter SJ (1983) Length, weight, and associated structural indices. In: Nielsen LA, Johnson DL (eds) Fisheries techniques. American Fisheries Society, Bethesda, pp 283-300

Bagenal TB (1978) Aspects of fish fecundity. In: Gerking SD (ed) Ecology of fresh water fish production. Blackwell, London, pp 75-101 
Cardinale M, Arrhenius F (2000) The relationship between stock and recruitment: are the assumptions valid? Mar Ecol Prog Ser 196:305-309

Du JR (1963) Studies on the reproduction and feeding habit of Bagrid Catfish in Liangzi Lake. J Zool Res 2:74-77, (in Chinese)

Heins DC, Baker JA (1993) Clutch production in the darter Etheostoma lynceum and its implications for life-history study. J Fish Biol 42:819-829

Hotosa GN, Avramidoua D, Ondrias I (2000) Reproduction biology of Liza aurata (Risso, 1810), (Pisces Mugilidae) in the lagoon of Klisova (Messolonghi, W. Greece). Fish Res 47:57-67

Hu CY, Hong YJ, Lin GH (1993) Gonad study of Pelteobagrus fulvidraco in spawning season. Jiangxi Science 11:159163, (in Chinese)

Hunter JR, Lo NCH, Leong R, Macewicz B (1985) Batch fecundity in multiple spawning fishes. In an egg production method for estimating spawning biomass of pelagic fish: application to the northern anchovy, Engraulis mordax (Lasker R ed.). NOAA Tech Rep NMFS 36:67-78

Hunter JR, Macewicz BJ, Lo NCH, Kimbrell CA (1992) Fecundity, spawning, and maturity of female Dover sole, Microstomus pacificus, with an evaluation of assumptions and precision. Fish Bull 90:101-128

Johnston CE, Knight CL (1999) Life-history traits of the bluenose shiner (Pteronotropis welaka) (Cypriniformes: Cyprinidae). Copeia 1999:200-205

Lei HZ, Lin ZH (2004) The sexual ratio of Pseudobagrus fulvidraco population in Oujiang River during reproductive time. Journal of Wenzhou Normal College 2:77-79, (in Chinese with English abstract)

Lin ZH, Lei HZ (2004) Sexual dimorphism and female reproductive characteristics of Pseudobagrus fulvidraco. Chinese Journal of Zoology 39:13-17, (in Chinese with English abstract)

Liu SP (1997) A study on the biology of Pseudobagrus fulvidraco in Poyang Lake. Chinese Journal of Zoology 32:10-16, (in Chinese with English abstract)

Liu WB, Zhang XJ (2003) Study on the development and annual change in the ovary of Pseudobagrus fulvidraco. Journal of Natural Science in Hunan Normal University 26:73-78, (in Chinese with English abstract)

Luo HB, Li LY, Yao WZ, Jiang YM (2005) Biological characters and resources management of Pseudobagrus fulvidraco in Zhangdu Lake. Freshwater Fisheries 5:2527, (in Chinese with English abstract)

Ma J (1991) Research on biology of Pelteobagrus fulvidraco in Honghu Lake. Bio-productivity exploitation and environment optimizing investigation of Honghu Lake. Ocean Press, Beijing, pp 150-160
Maack G, George MR (1999) Contributions to the reproductive biology of encrasicholina punctifer Fowler, 1938 (engraulidae) from West Sumatra, Indonesia. Fish Res 44: $113-120$

Mattson NS (1991) A new method to determination sex and gonad size in live fishes by using ultrasonography. J Fish Biol 39:673-677

Mazzoni R, Iglesias-Rios R (2002) Environmentally Related Life History Variations in Geophagus brasiliensis. J Fish Biol 61:1606-1618

Morgan DL, Gill HS, Potter IC (2000) Age composition, growth and reproductive biology of the salamanderfish Lepidogalaxias salamandroides: a re-examination. Environ Biol Fisches 57:191-204

Murua H, Motos L (2006) Reproductive strategy and spawning activity of the European hake Merluccius merluccius (L.) in the Bay of Biscay. J Fish Biol 69:1288-1303

Murua H, Kraus G, Saborido-Rey F, Witthames PR, Thorsen A, Junquera S (2003) Procedures to estimate fecundity of marine fish species in relation to their reproductive strategy. J Northwest Atl Fish Sci 33:33-54

Murua H, Lucio P, Santurtun M, Motos L (2006) Seasonal variation in egg production and batch fecundity of European hake Merluccius merluccius (L.) in the Bay of Biscay. J Fish Biol 69:1304-1316

Pearce A (1965) A manual for histological technicians, 2nd edn. Little, Brown and Co., Boston, MA

Qiu CG, Liu JZ, Liu BY, Xu SQ, Zhang GQ, Luo XN (2000) Biology and resource management of Pelteobagrus fulvidraco in Tanghu Lake. Fish Sci 2:28-30, (in Chinese)

Wang WM (1999) Artificial breeding trial of Pseudobagrus fulvidraco. Fish Sci 18:9-12, (in Chinese)

Wang WM, Yan AS, Zha JM (2002) Comparison of two artificial breeding methods of Pseudobagrus fulvidraco. Freshwater Fisheries 32:7-8, (in Chinese with English abstract)

Xiao XL, Ou YM, Zhang M, Tao QH, Wei HM, Lv L (2002) Study on some biological characters of Pelteobagrus fulvidraco in Poyang Lake. Acta Agriculturae Jiangxi 14:18-22, (in Chinese with English abstract)

Xiao TY, Zhang HY, Wang XQ, Xiao KY, Dai KY (2003) Biological characters of Pseudobagrus fulvidraco in Dongting Lake. Chinese Journal of Zoology 38:83-88, (in Chinese with English abstract)

Yang JY (1994) Reproductive biology of Pelteobagrus fulvidraco in Jialing River. Journal of Southwest Normal University (Science) 19:639-645, (in Chinese with English abstract)

Zou SX, Tian BP (1998) Study on biology and fishery of Pelteobagrus fulvidraco in Taihu Lake. Journal of Sichuan Institute of Animal Husbandry and Veterinary Medicine 12:36-41, (in Chinese with English abstract) 